\title{
Surficial sediment texture database for the south-western Iberian Atlantic margin
}

\author{
Susana Costas, Margarida Ramires, Luisa B. de Sousa, Isabel Mendes, and Oscar Ferreira \\ Centre for Marine and Environmental Research-CIMA, University of Algarve, Faro, 8005-139, Portugal \\ Correspondence: Susana Costas (scotero@ualg.pt)
}

Received: 1 March 2018 - Discussion started: 3 April 2018

Revised: 11 June 2018 - Accepted: 13 June 2018 - Published: 22 June 2018

\begin{abstract}
Assessing the impact of changes on the environment driven by natural or anthropogenic forcers includes the comparison between antecedent and post-event conditions. The latter is particularly relevant in order to better understand to which extent those changes actually impact or alter a particular environment and associated services and to determine the resilience of a system. In this regard, it becomes essential to create or provide databases to inform about baseline conditions. Here, we present a database that integrates surficial sediment samples collected and analysed for textural characterization within the framework of a series of research projects over circa 20 years. Collected samples along the south-western Atlantic margin of the Iberian Peninsula extend from estuaries and beaches to the adjacent continental shelf. For the case of the more dynamic environments, namely coastal sandy barriers, samples were repeated over time in order to capture the intrinsic variability of the system. Examples of the utility of this data set for a variety of purposes and environments are also included within this paper through three examples. Therefore, here we show the added value of the database as it can be used to assess the impact of a particular event or activity at an estuary by providing baseline conditions, evaluate the continental shelf sediment suitability for nourishment activities, or contribute to the understanding of the morphodynamics and classification of beaches. Finally, it is worth stating the importance of such databases to analyse medium- to long-term variability as the one induced by sea level rise, changes in storminess, or human activities. The open-access data presented here are at https://doi.org/10.1594/PANGAEA.883104.
\end{abstract}

\section{Introduction}

Grain size is the most fundamental physical property of sediments. It has been found to determine to a great extent the mode, distance, and amount of material that can be transported by a fluid (e.g. Bagnold, 1941, 1956; Rijn, 1993; Shields, 1936; Soulsby, 1997), the slope of beaches (e.g. Bascom, 1951; Sunamura, 1984), the permeability and stability of structures in civil engineering (e.g. Look, 2007; Terzaghi et al., 1996), kinetic reactions and affinities of heavy metals and other contaminants (e.g. Ackermann et al., 1983; Andrieux-Loyer and Aminot, 2001; Krumgalz, 1989), or even the distribution of benthic communities (e.g. Cahoon et al., 1999; Gibson and Robb, 1992; McLachlan, 1996; Yang et al., 2008). Likewise, and assuming the aforementioned controls that this property may exert, grain size is used as an environmental proxy to identify and reconstruct sediment trans- port pathways (e.g. Gao and Collins, 1992, 1994; Le Roux, 1994; Le Roux and Rojas, 2007), past records of wind intensity (Lindhorst and Betzler, 2016), changes in the processes generating windblown sediments (Vandenberghe, 2013), and changes in the strength of continental shelf currents and precipitation regimes over time (Gyllencreutz et al., 2010), or to infer driver-related energy gradients (Rosa et al., 2013).

The above also suggests that a big effort has been made over time to determine this property of sediments, in particular when exploring surficial sediments. However, in many cases, the generated data are only partially and diffusively published, with most of the information not being available to the scientific community or to stakeholders. Often, stakeholders spend extra resources to characterize areas (to be managed or under analysis) where basic background already exists but is not easily available nor public. That is the 


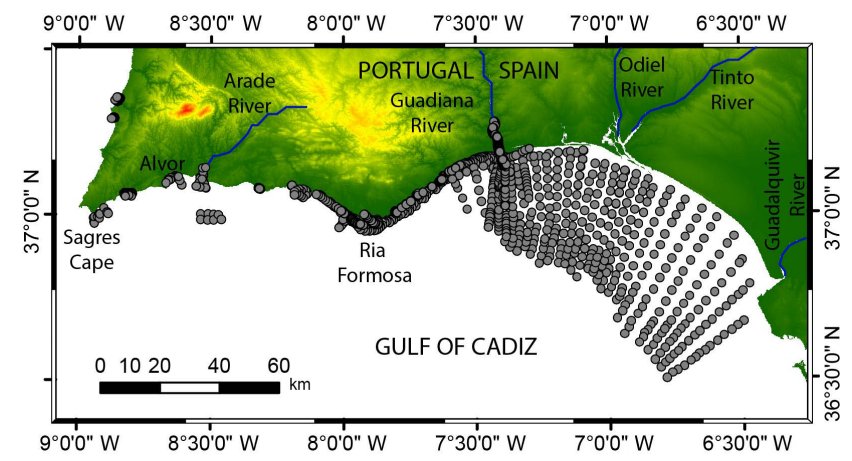

Figure 1. Distribution of the samples that conform to the IBAMSed database along the southern Atlantic coast of the Iberian Peninsula. The Supplement to this paper includes the spatial distribution of the samples that conform to the IBAM-Sed database as shape files. The shape files are also openly accessible for download within a data set at https://doi.pangaea.de/10.1594/PANGAEA.890946.

case of a large number of sediment samples collected within the framework of diverse Portuguese, Spanish, and European funded projects whose results for the Atlantic margin of the Iberian Peninsula (namely the coast and the adjacent continental shelf) remain unpublished.

Here, we present a recently created database, IBAM-Sed the Iberian Atlantic Margin Sediments database. IBAM-Sed compiles all available information about the textural properties of surface sediments along the southern Atlantic coast and shelf of the Iberian Peninsula collected within the framework of 24 projects (Fig. 1). The samples include sediments from emerged beaches, estuaries, a coastal lagoon, and the adjacent continental shelf. The objective of this compilation is to make all this information available to the community as it might support future decision making or even serve as a reference to assess the impact of specific activities over time. To illustrate the latter, we show the potential use of some of the data included in the database with three examples. The first shows how the database can be used to assess changes in the bed-surface sediment distribution within the Guadiana River estuary after the construction upstream of a large-scale dam. The second example shows how the aforementioned database can be used to map and assess the resources within the adjacent shelf for sand mining for beach nourishment purposes. Finally, the third example shows how the database can also support the morphodynamic classification of beaches using mean grain sizes.

\section{Data}

\subsection{Data origin}

A total of 4727 samples were collected within the framework of 24 projects developed between 1996 and 2015 along the southern Atlantic coast of the Iberian Peninsula. The projects had different purposes, including fishing exploration, ben- thic characterization, continental shelf evolution during the Holocene, coastal dynamics investigation, or monitoring of nourished beaches. The variety of the projects explains the variety of environments that have been sampled and compiled within this database and also the non-uniformity of the sample distribution across the overall area of interest. Data collection was performed by hand (at beaches and inlets) and using grab samplers (at the shelf). Table 1 summarizes the name of the projects, the sampled environments, the dates, and the total number of samples collected within each research project. The entire database is openly accessible at https://doi.org/10.1594/PANGAEA.883104.

\subsection{Textural analysis}

All collected samples were examined and analysed in order to determine their grain-size distribution. Due to the diversity of environments sampled and the subsequent variety of sediments, different methods were used to determine grainsize properties, i.e. sieving, pipette, and sedimentation balance methods. Organic matter was removed from the samples by using hydrogen peroxide at increasing concentrations $\left(10,30,80\right.$, and $\left.130 \mathrm{vol} \mathrm{L}^{-1}\right)$. Fine (silt and clay) and coarse (sand and gravel) fractions were separated by wet sieving using a $63 \mu \mathrm{m}(4 \phi)$ sieve. For samples containing a significant amount of sediments within the fine fractions $(<63 \mu \mathrm{m})$, the grain-size analysis was made using the pipette method that estimates the particle-size distribution from the rate at which particles sink through a fluid. The coarser fractions ( $>63 \mu \mathrm{m}$ ) of the samples were analysed through dry sieving, by using a sieve column (at $0.5 \phi$ or $\phi$ intervals) placed in a mechanical shaker for $20 \mathrm{~min}$. Projects CRIDA, EMERGE, SIRIA, and SIMPATICO were analysed at $\phi$ intervals. The material retained in each sieve was weighted. In the specific case of the EMERGE project, the main fractions were separated by wet sieving and the sand fraction was analysed by using the sedimentation balance method. The results from each size fraction, even if obtained from different methods (e.g. pipette, dry sieving), were merged to obtain the textural parameters for each sample.

The obtained and provided information on the grain size of the samples includes the main parameters used to texturally characterize the sediment samples, including the percentage per main size fraction (i.e. gravel, sand, and mud), the mean grain size $(\phi)$, the sorting $(\phi)$, the kurtosis, the modes $(\phi)$, and the skewness. Despite the textural parameters within the database referring to the logarithmic $(\phi)$ scale, the maps presented in this paper have been elaborated using the metric scale $(\mathrm{mm})$ to facilitate the images' interpretation by a broader audience.

In most of the projects, the parameters were calculated by applying the Folk and Ward (1957) logarithmic method by using GRADISTAT (Blott and Pye, 2001), a program that runs in Microsoft Excel and is suitable for calculating particle-size statistics for sieving or other methods frequently 
Table 1. Summary of the projects contributing information to the present database of surficial sediments, including the type of sampled environment, dates, number of samples, and technical DOI reference for each particular data set within the entire database. All data sets are aggregated in a parent set, which represents the entire data set and whose citation DOI is doi.pangaea.de/10.1594/PANGAEA.883104.

\begin{tabular}{|c|c|c|c|c|}
\hline Project & Sampled environment & Date(s) & No. of samples & Data set technical DOI \\
\hline BAYBEACH & Beach & 2007 to 2012 & 403 & https://doi.pangaea.de/10.1594/PANGAEA.883092 \\
\hline MESHATLANTIC & Continental shelf & 2011 & 22 & https://doi.pangaea.de/10.1594/PANGAEA.883091 \\
\hline SIMCO & Estuary & 2015 & 22 & https://doi.pangaea.de/10.1594/PANGAEA.883079 \\
\hline GESTEPESCA & Beach (nearshore) & 2005 & 212 & https://doi.pangaea.de/10.1594/PANGAEA. 883073 \\
\hline CLIFF & Beach & 2010-2012 & 218 & https://doi.pangaea.de/10.1594/PANGAEA.883083 \\
\hline EROS & Beach & $2011-2012$ & 247 & https://doi.pangaea.de/10.1594/PANGAEA.883090 \\
\hline MOSES & Beach & 2011 & 1167 & https://doi.pangaea.de/10.1594/PANGAEA.883084 \\
\hline COASTMONITOR & Beach & 1996-1998 & 455 & https://doi.pangaea.de/10.1594/PANGAEA.883098 \\
\hline REQLAGOONRF & Beach & 1999-2000 & 100 & https://doi.pangaea.de/10.1594/PANGAEA.883112 \\
\hline NEWSLUISINLET & Beach & 1997 & 45 & https://doi.pangaea.de/10.1594/PANGAEA.883080 \\
\hline INDIA & Beach, lagoon & 1997-1999 & 260 & https://doi.pangaea.de/10.1594/PANGAEA.883076 \\
\hline CROP & Lagoon, beach, inner shelf & 2001-2004 & 285 & https://doi.pangaea.de/10.1594/PANGAEA.883075 \\
\hline BERNA & Lagoon & $2005-2008$ & 20 & https://doi.pangaea.de/10.1594/PANGAEA.883093 \\
\hline MICORE & Beach & 2009 & 14 & https://doi.pangaea.de/10.1594/PANGAEA.883081 \\
\hline RUSH & Beach, lagoon & 2012-2013 & 15 & https://doi.pangaea.de/10.1594/PANGAEA.883078 \\
\hline GRADBENTHICRF & Lagoon & 2015 & 9 & https://doi.pangaea.de/10.1594/PANGAEA.883077 \\
\hline IDEM & Lagoon & 2006-2007 & 66 & https://doi.pangaea.de/10.1594/PANGAEA.883094 \\
\hline INLET-IPTM & Lagoon & 2001-2005 & 221 & https://doi.pangaea.de/10.1594/PANGAEA.883082 \\
\hline SHORE & Beach & 2013-2014 & 65 & https://doi.pangaea.de/10.1594/PANGAEA.883103 \\
\hline SIRIA & Continental shelf & 1999-2001 & 522 & https://doi.pangaea.de/10.1594/PANGAEA.883074 \\
\hline EMERGE & Estuary & 2000 & 284 & https://doi.pangaea.de/10.1594/PANGAEA.883087 \\
\hline SIMPATICO & Estuary & 2008 & 6 & https://doi.pangaea.de/10.1594/PANGAEA. 883088 \\
\hline CRIDA & Beach & 2003 & 48 & https://doi.pangaea.de/10.1594/PANGAEA.883086 \\
\hline CIRCO & Continental shelf & 2010 & 21 & https://doi.pangaea.de/10.1594/PANGAEA.883085 \\
\hline
\end{tabular}

used to obtain the grain-size distribution. In other projects, i.e. EMERGE and SIRIA, the logarithmic method of the moments (Friedman and Sanders, 1978) was applied, but not using GRADISTAT because the program was only developed later.

\subsection{Meta-information}

The database is divided into 24 events or files, each corresponding to the project within the framework in which the samples were collected. The information provided within the database includes references to the location of each sample (latitude, longitude and elevation, or depth), the method used to collect the sample and to determine the grain-size distribution, as well as the main textural parameters and the method used to calculate them, following the recommendations by PANGAEA. The data are available as txt files and openly accessible at https://doi.org/10.1594/PANGAEA.883104. Additionally, the data are also available for visualization at http://www.cima.ualg.pt/IBAM-Sed.

The diverse objectives of the projects behind the database explain the differences in the frequency of the retrieved samples. Samples related to projects focused on relatively stable zones, or those whose objectives do not include any monitoring strategy, have been collected only once (e.g. the MESHATLANTIC project, Table 1). Alternatively, samples related to the monitoring of sandy beaches have been repeated over time following seasonal (e.g. the CLIFF and BAYBEACH projects, Table 1) or even monthly (e.g. the MOSES project, Table 1) intervals for the duration of the project.

\section{Spatial coverage and grain-size distribution}

The database covers the southern coast of Portugal and extends to the east until the continental shelf off the Guadalquivir River, covering therefore a large portion of the northern Gulf of Cadiz (Fig. 1). Therefore, the sampled area includes the continental shelf influenced by the main rivers on the Atlantic southern coast of the Iberian Peninsula, i.e. the Guadiana and the Guadalquivir (Fig. 1) and the Tinto and Odiel rivers. Towards the west, the shelf is more dispersedly sampled, with samples off Ria Formosa and the Arade estuary, off the Alvor coastal lagoon and the Sagres cape (Fig. 1). In addition, the database includes surface sediment samples collected at the Arade and Guadiana estuaries and also inside the Ria Formosa coastal lagoon, and at several beach locations along the Algarve and Andalusian coast. A shape file representing the spatial distribution of each project integrating the database was created for download as a Supplement in the repository of Copernicus. The shape files are also openly accessible as further details at 

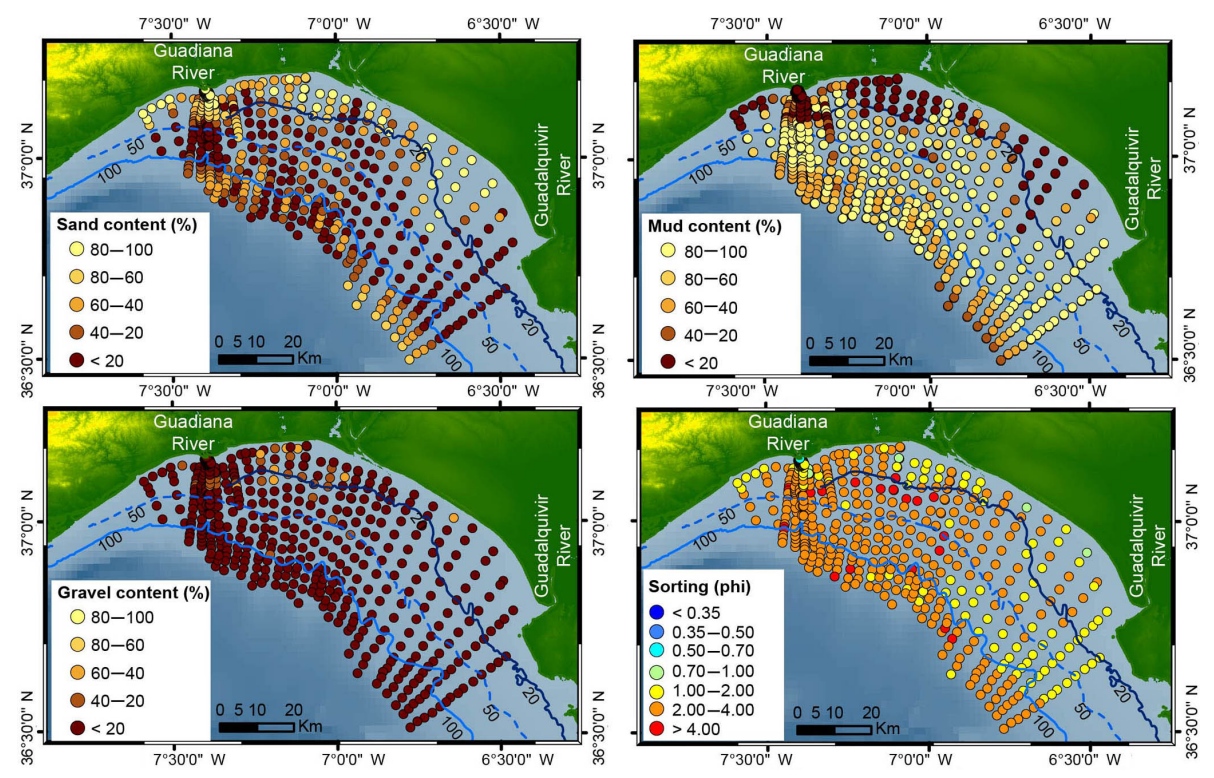

Figure 2. Surface distribution of the content of sand, mud, gravel, and the sediment sorting within the area of the continental shelf more densely sampled within IBAM-Sed. The sediment sorting was estimated using the logarithmic method of the moments (Friedman and Sanders, 1978). The shape file showing the distribution of the surface sediment samples is openly accessible for download within a data set at https://doi.pangaea.de/10.1594/PANGAEA.890946.

https://doi.org/10.1594/PANGAEA.883104 and at the data set https://doi.pangaea.de/10.1594/PANGAEA.890946.

The overall data included in the database were never examined in a complete and integrated way. However, some of the samples were carefully studied and published as part of the results of the related projects. This is the case of the continental shelf surface sediments off the Guadiana-Guadalquivir rivers.

A surface sediment textural description has been elaborated in Gonzalez et al. (2004) using a part of the data included in the database. According to the authors and the database, sandy deposits down to a depth of approximately $25 \mathrm{~m}$ (Fig. 2) characterize the continental shelf off Guadiana, despite several patches of sandy mud and mud (Gonzalez et al., 2004). The middle shelf is dominated by an extensive mud belt, consisting of very fine-grained clayey material. On the outer shelf, below $100 \mathrm{~m}$, sediments are generally dominated by sandy and silty clay. These are interrupted locally by large patches of muddy sand and slightly muddy sandy gravel in the vicinity of the shelf edge (Fig. 2). Therefore, the main components of the sediment in this area are sand and mud despite the occurrence of samples with percentages of gravel above $50 \%$ within the vicinity of the Guadiana River outlet and to the east of it (Fig. 2). In general terms, the surface distribution of the standard deviation of the sediment, following the logarithmic method of moments, indicates that they are very poorly sorted (values between 2 and $4 \phi$ ), which are coincident with the areas with higher sand content. Poorly sorted sediments $(1-2 \phi)$ were found in the vicinity of the Guadalquivir River, which is dominated by mud sediments, and off the Guadiana and Tinto-Odiel rivers, dominated by sandy sediments (Fig. 2).

Towards the west, the inner shelf surrounding the Ria Formosa barrier island system was systematically sampled (Fig. 3), allowing a detailed description of the surface sediment distribution (Rosa et al., 2013). The finest sediments (i.e. coarse silt; $31-63 \mu \mathrm{m}$ ) were found at the updrift margin of the Guadiana inlet, while coarser sediments (i.e. very coarse sand; $1-2 \mathrm{~mm}$ ) were found within the updrift end of the system at Olhos de Água (Rosa et al., 2013). Between these two extremes, there is a general increase in the mean grain size towards the east from fine sand dominating the western nearshore flank of the barrier island system to very coarse sand (Fig. 3). The latter trend appears related to a decrease in the incident wave energy and an increase in biogenic grains of the autochthonous benthonic communities (Rosa et al., 2013). In fact, the increase in the amount of biogenic grains (i.e. shell fragments) also explains the shift towards poorly sorted sediments to the east (Fig. 3).

The remaining areas of the southern Portuguese continental shelf have been poorly sampled, with some samples collected off the Arade estuary, within the transition between the inner to middle shelf, and a few more samples off the Sagres cape (Fig. 1). The results document coarser sediments, moderately to very poorly sorted medium to very coarse sand, within the shelf off the Arade estuary, and very well to wellsorted medium to fine sands off the Sagres cape (Fig. 4).

Regarding the beaches along the southern Portuguese coast, a total of 24 beaches have been sampled and included within the database, covering most of the Algarve coast from 


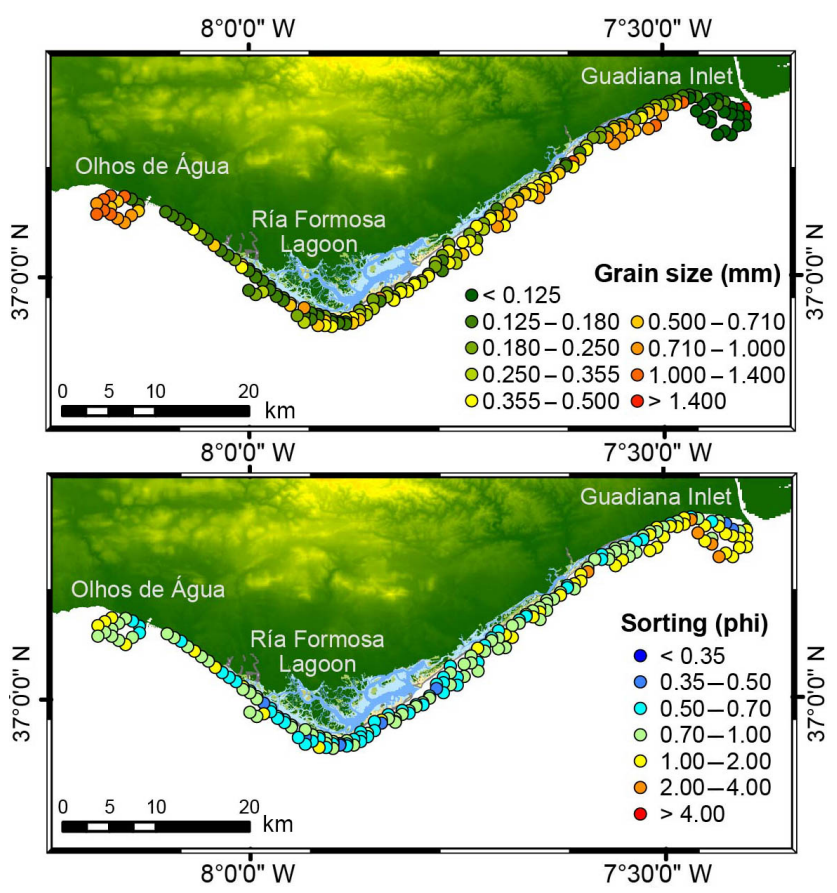

Figure 3. Mean grain size and sediment sorting surface distribution on the inner shelf from Olhos de Água to the Guadiana River mouth. Mean grain size and sediment sorting were estimated using the Folk and Ward (1957) logarithmic method. The shape file showing the distribution of the surface sediment samples is openly accessible for download within a data set at https://doi.pangaea.de/10.1594/ PANGAEA.890946.

the western margin to its eastern end (Fig. 4). Some of the beaches, in particular those within the peninsulas or barrier islands of Ria Formosa, have been re-grouped into 18 sites as shown in Fig. 4. In some cases, the sedimentological characterization of most sampled beaches extended seaward, including the nearshore area (Table 1), and also landward, including the dune. In general terms, the beaches are dominated by medium sand (around $0.3 \mathrm{~mm}$ ) along the western part of the studied area with a sudden increase in the mean grain size in the Galé-Olhos de Água region (sites 7 and 8 in Fig. 4). To the east of this region, the mean grain size tends to decrease despite relatively high values at site 12 (Fig. 4). Regarding the sorting of the analysed sediments, the results document an increase in the value of the sorting parameter that translates into poorer selection towards the east, with very well-sorted $(<0.35)$ sediments within the westernmost subaerial beaches and moderately well-sorted $(0.50-0.70)$ sediments in most of the rest of the beaches (Fig. 4).

As aforementioned, two estuaries and one lagoon are included in the database (Fig. 1). The Guadiana estuary, by far the example better represented in terms of sampling density, is characterized by well-sorted medium sand at the lower estuary, while gravels can be found at the deepest locations, either mixed with sand or in small isolated pockets (Garel,

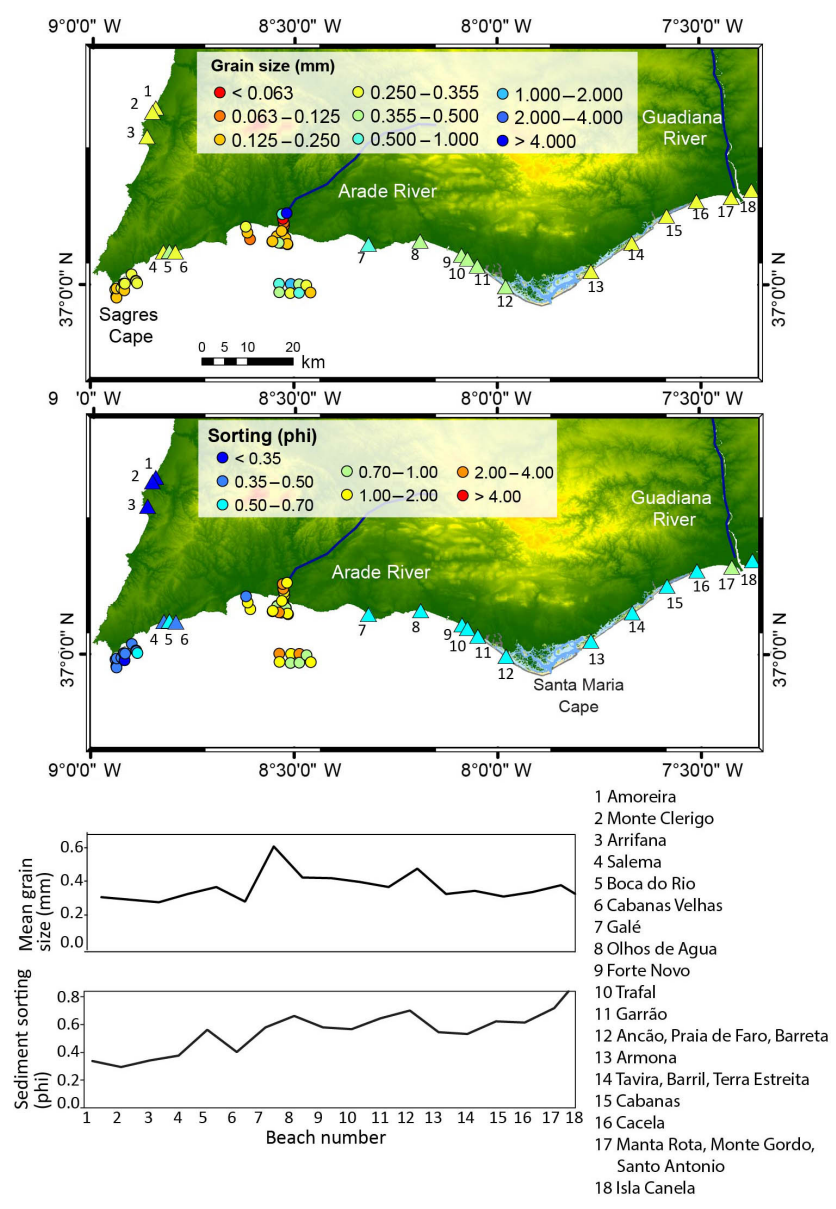

Figure 4. Distribution of the mean grain size and sediment sorting at the different sampled beaches, Arade estuary, and localized areas within the continental shelf. Mean grain size and sediment sorting of the 24 sampled beaches (grouped into 18 sites marked with triangles in the map) are also presented in the lower panels to more clearly show the longshore variability. Mean grain size and sediment sorting were estimated using the Folk and Ward (1957) logarithmic method. The shape files showing the distribution of the surface sediment samples are openly accessible for download within a data set at https://doi.pangaea.de/10.1594/PANGAEA.890946.

2017). Muddy very fine sands are found within the transition between the deep channel and the shallow domains (Garel, 2017). The shallower marginal areas consist of muddy sediments. The few samples collected within the Arade estuary point towards a high diversity of grain sizes without a clear distribution trend; medium gravel grain sizes have been found within the inner estuary, while silty to very fine sands can be found at the outer estuary (Fig. 4). In the same line, the sorting of the sediment ranges between poorly to very poorly sorted with moderately sorted sediments within the vicinity of the estuary mouth. The Ria Formosa lagoon is not completely represented as performed projects and thus related sampling mainly focussed on monitoring tidal inlets and navigational channels (Figs. 1 and 5). The latter is mainly related 


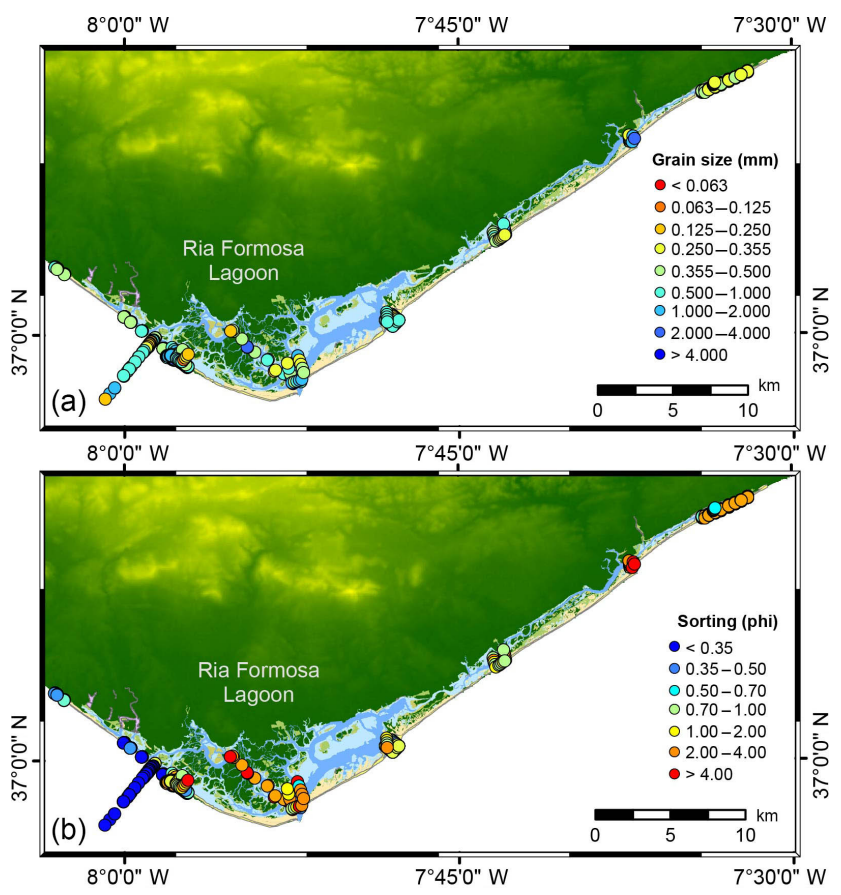

Figure 5. Spatial distribution of surface sediment samples showing mean grain sizes (a) and sediment sorting (b) within the Ria Formosa barrier island system. Mean grain size and sediment sorting were estimated using the Folk and Ward (1957) logarithmic method. The shape files showing the distribution of the surface sediment samples are openly accessible for download within a data set at https://doi.pangaea.de/10.1594/PANGAEA.890946.

to the fact that Ria Formosa hydrodynamics and morphodynamics are dominated by the multi-inlet system with six tidal inlets from which two have been artificially fixed, three that have been artificially relocated, and one that evolves naturally. The results document the presence of heterogeneous sediments within the Ria Formosa tidal inlets and sampled channels ranging from very fine gravels within most of the tidal inlets to very fine sands within the back-barrier beaches (Fig. 5), reflecting the differences in hydrodynamics. In general terms, the sediment within the inlets and inner channels is very poorly sorted. Very poorly sorted sediments can also be found within eastern beaches, while the western ones are very well sorted (Fig. 5).

\section{Application of the database}

The present work also intends to illustrate through three examples the utility of the database here presented. The first case exemplifies how the database can be used to define a baseline situation to assess changes in the bed-surface sediment distribution. For that, we have used the results of the sediment textural analysis within the Guadiana River estuary collected before the construction upstream of a largescale dam. The second case shows how the aforementioned database can be used to find the sand and gravel mining resources within the adjacent shelf for beach nourishment purposes. Finally, the third example shows how the data from beaches can be used in combination with other sources of information, beach slope and incident wave characteristics in this case, to define the typical morphodynamic state of the sampled beaches.

\subsection{Setting up baseline conditions}

On 8 February 2002 the Alqueva dam was inaugurated in the Guadiana River with the aim of reinforcing the capacity of hydroelectric production, developing tourism, promoting regional employment, organizing intervention in environmental and patrimony domains, fighting physical desertification and climate change, modifying the agriculture model of southern Portugal, and regularizing river flow (Morais, 2008). With this new dam, built $60 \mathrm{~km}$ upstream from the estuary head, the regulation of the river flow increased from 75 to $81 \%$ (Rocha et al., 2002). The latter had significant consequences for the downstream phytoplankton communities (Domingues et al., 2007, 2014) and the volume of coarse sediment exported from upstream (Dias et al., 2004), and might have consequences for fish populations (Morais, 2008). The reduction of coarse sediment exported to the estuary from upstream sources and the river flow regulation with the reduction (absence) of floods since 2001 could also provoke a change in the grain-size distribution within the estuary itself that has not yet been assessed (Dias et al., 2004).

The samples were collected between September and October 2000 in the lower Guadiana estuary, together with a bathymetric survey (Fig. 6). The distribution of the main sediment components (i.e. mud, sand, and gravel) shows a clear dominance of the sand fraction over the rest of the components clearly concentrated within the mid-channel (Fig. 6). The percentage of mud gradually increases upstream, while the gravels appear to concentrate in the deepest areas of the estuary. This situation represents a baseline image of the conditions of the estuary prior to the construction of the Alqueva dam built within the Guadiana basin. The baseline situation presented here can be used to assess changes derived from the dam construction by comparing with a new grain-size survey and analysis. That would provide insights into, for instance, areas of increasing/decreasing deposition of coarser sediments versus increasing/decreasing deposition of finer sediments due to the lower fluvial hydrodynamics.

\subsection{Identification of sand banks}

Beach nourishment is recognized as an environmentally friendly method of shore protection, being the method of choice for shore protection along many developed coasts with eroding beaches (Finkl and Walker, 2005). It is a practical method use for protecting against storm-induced coastal flooding or erosion and structural shoreline retreat. It is also 

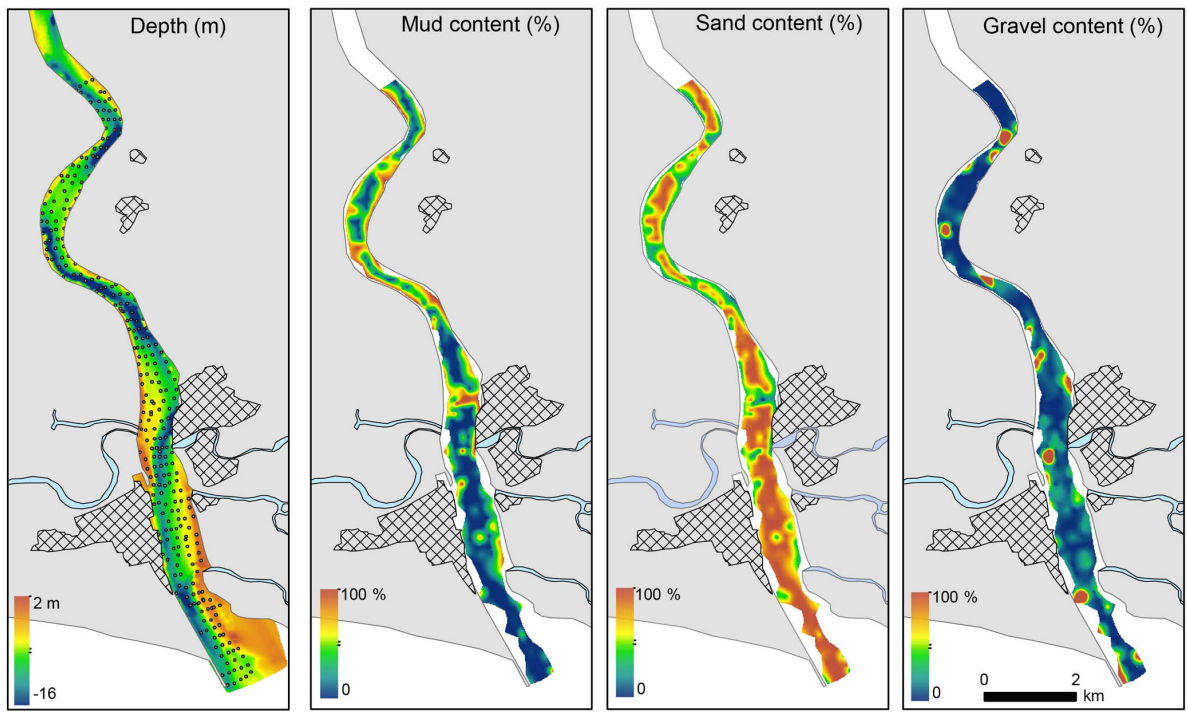

Figure 6. Sediment distribution along the lower Guadiana estuary and contents of the main sediment fractions: mud, sand, and gravel. The shape files showing the distribution of the surface sediment samples are openly accessible for download within a data set at https: //doi.pangaea.de/10.1594/PANGAEA.890946.

often used for shifting the shoreline seaward and for widening recreational beaches. Beach nourishment projects are complicated technical procedures that require careful preparation for successful execution of site-specific engineering design (Finkl and Walker, 2002). The grain size of the borrow material is one of the most important factors for optimizing beach nourishment, with several authors agreeing that coarser grain sizes produce steeper, more stable, and longerlived fills (Finkl and Walker, 2005). Sand used in beach nourishment projects is mostly dredged from borrow areas at the seafloor (nearshore and inner shelf). That sediment should be obtained at depths greater than the local depth of closure (depth below which no relevant sediment exchanges occur between the nearshore and the adjacent shelf). Other sources of sand include inlet dredging, channel dredging, or sand retained at cross-shore obstacles (e.g. harbour jetties or breakwaters). Portuguese law defines that all sand (with acceptable or good quality) extracted from the coastal area and up to approximately $2 \mathrm{~km}$ from the coast must be used as beach nourishment.

To ensure that beach nourishment projects have a higher possibility of success, it is thus necessary to have consistent and detailed data on both beach and borrow area grain size and distribution. The presented database includes both and can then serve as a tool to plan beach nourishment by providing information on the grain sizes and their variability from beach to beach and by allowing an easy comparative analysis of the compatible sediments located at the shelf or even at channels and inlets, which can be subjected to potential dredging. Figure 7 shows two areas of compatible sediments to exemplify the utility of the database, (1) a beach located downdrift of the Guadiana River mouth and whose retreat forced the authorities to nourish in 2005 (Garel et al., 2014), and (2) an area located at the shelf, seaward of the depth of closure, which in this area is located at circa $10 \mathrm{~m}$ water depth (Dolbeth et al., 2007), where sediments have compatible sizes and very low fine contents. It can also be observed that to the east the sediments start to have a larger percentage of fine material, making them unsuitable for nourishment purposes.

\subsection{Characterizing beach morphodynamics}

Beach morphodynamics refers to the mutual adjustment of hydrodynamic processes (principally shoaling-breaking swash waves, tide, and wind), the sediment of the beach environment, and any other boundary conditions, in an attempt to maintain a dynamic equilibrium (Wright and Thom, 1977). The development of a morphodynamic approach to beach studies in the 1970s provided a major new paradigm that transformed the way beaches were studied and allowed considerable progress in the understanding and study of beach systems (Short, 1999). This notion has resulted in the formulation of beach-type classifications that recognize and categorize the different morphodynamic signatures within distinct beach morphologies or states, and link these to parameterizations related to key environmental conditions, namely wave climate, tidal regime, and beach sediment characteristics. The most widely used of these models is the socalled Australian beach classification model, originally formulated by Chappell and Eliot (1979), Short (1978), and Wright et al. (1979), and subsequently modified by Wright and Short (1984). This approach enabled the full spectrum of wave-dominated micro-tidal beach systems and types to be 


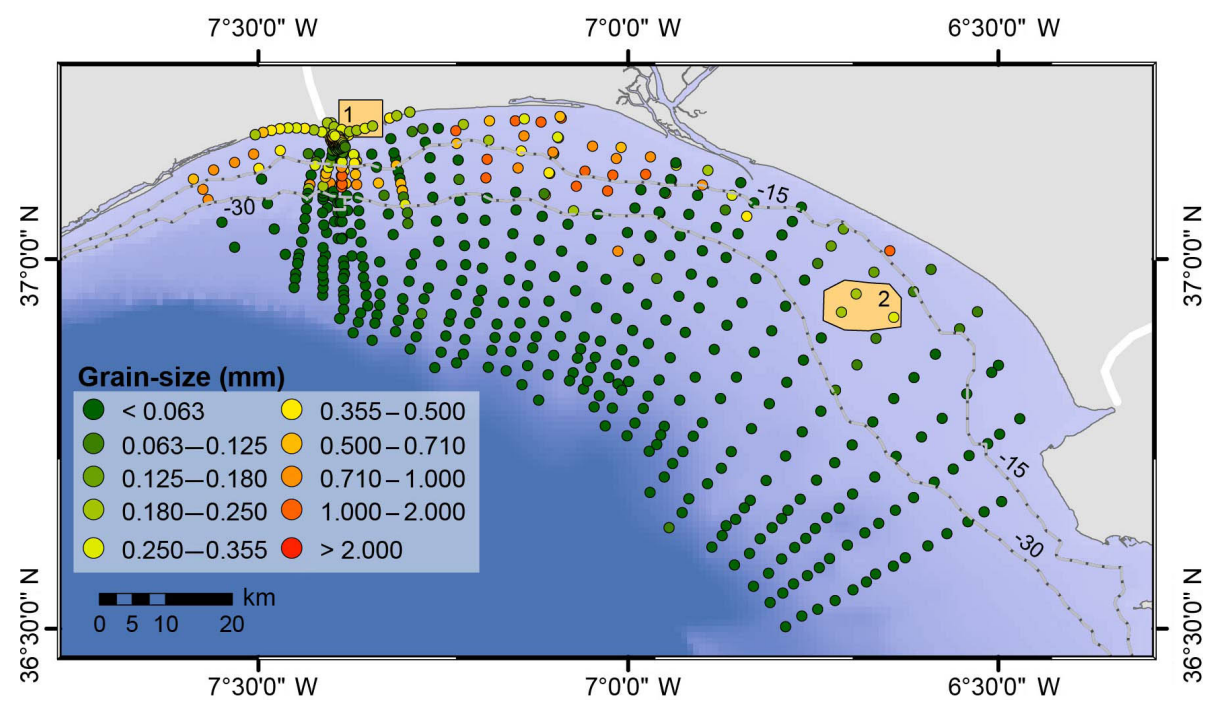

Figure 7. Surface mean grain size within the sampled continental shelf and adjacent beaches with evident problems of land loss. The orange boxes show (2) an area within the continental shelf whose sediments are compatible with the sediments at the beaches presenting erosion problems (1). Submerged samples were collected within the framework of the SIRIA project and mean grain sizes were estimated by applying the logarithmic moments method (Friedman and Sanders, 1978). Emerged samples, located along the shoreline, were collected within the framework of the CRIDA project and mean grain sizes were calculated by applying the Folk and Ward (1957) logarithmic method. The shape files showing the distribution of the surface sediment samples are openly accessible for download within a data set at https://doi.pangaea.de/10.1594/PANGAEA.890946.

identified and characterized and is utilized to examine beach response at different timescales. However, the latter did not include beach signatures derived from the effect of tides until Masselink and Short (1993) introduced a parameterization of the relative importance of tides and waves by the relative tide range (RTR) given by MSR / $H_{\mathrm{b}}$, where MSR is the mean spring tide range and $H_{\mathrm{b}}$ is the modal breaking wave height. Therefore, this model classifies beaches using two dimensionless parameters, the RTR and the dimensionless fall velocity $\Omega=H_{\mathrm{b}} / w_{\mathrm{s}} T$, where $w_{\mathrm{s}}$ is the sediment fall velocity according to Ahrens (2000) and $T$ is the wave period.

Figure 8 shows the location of the 18 groups of sediment types derived from the 24 sampled beaches whose sediments were characterized using the mean grain size from the present database and the result of the morphodynamic classification of those beaches after applying the required additional parameters (i.e. $H_{\mathrm{b}}, T$, and MSR). Wave climate characterization for the beaches at the southern coast (beaches 4 to 18 in Fig. 8) was based on the available data set from the Faro buoy for the period 1993-2013, located offshore from Ria Formosa at $93 \mathrm{~m}$ depth (Fig. 8). The wave climate of the beaches located along the western coast (beaches 1 to 3 in Fig. 8) was characterized using offshore hindcast wave data covering the same time interval (SIMAR data set, code 5006023) provided by Puertos del Estado and that were used to characterize wave climate along the western coast. Wave refraction and shoaling were calculated using linear wave theory and combined with the breaking criterion $\Upsilon_{\mathrm{b}}=H_{\mathrm{b}} / d_{\mathrm{b}}=0.78$ to estimate $H_{\mathrm{b}}$ at each beach consider- ing beach orientation, where $d_{\mathrm{b}}$ is the breaking depth. Waves approaching a particular beach with an angle greater than $70^{\circ}$ were not considered for the analysis as the objective was to find the modal wave dominance at each beach. The classification documents a longshore variability in the type of beaches, suggesting the low tide terrace and low tide bar types as the more frequent ones along the southern coast. However, the classification clearly separates the beaches at the eastern flank of Ria Formosa and in the vicinity of Sagres (low tide bar, mostly intermediate) from the rest of the beaches on the southern coast (mostly reflective), which are included within the low tide terrace type (Fig. 8). This separation appears mostly related to the different nature of the sediment or grain size, the latter being greater within the second group (Fig. 8). In turn, the beaches located along the western coast have been classified as barred beaches, showing a tendency to more dissipative morphotypes. In this case, the greater wave break height within this area seems to mostly explain this result.

\section{Data availability}

The results from the textural analysis of 4727 surface sediment samples from the south-western Atlantic coast of the Iberian Peninsula have been compiled within IBAM-Sed database, which is described in this paper and is available from the PANGAEA data archive. The database consists of 24 datasets that correspond to each of the projects within which the sediment samples were 

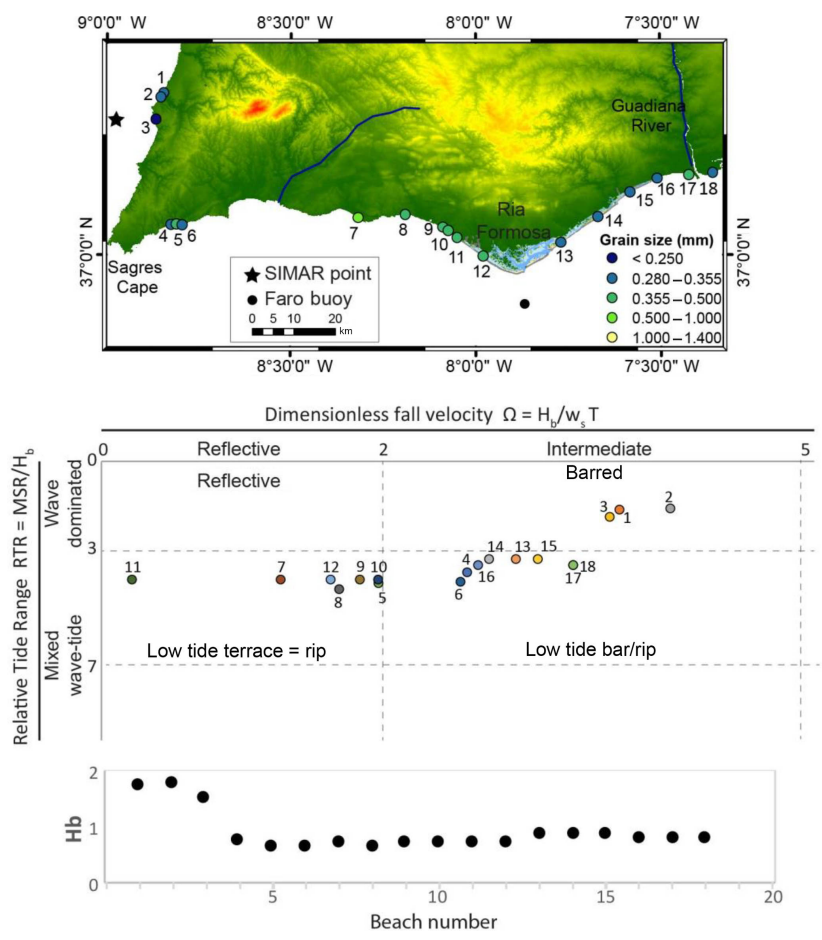

Figure 8. Map showing the location and mean grain size of the sampled beaches and the result of the morphodynamic classification using the Masselink and Short (1993) model. Finally, the lower graph shows the longshore variability of the modal breaking wave height used for the classification. Mean grain sizes were estimated using the Folk and Ward (1957) logarithmic method.

collected and analysed, and it is openly accessible at https://doi.org/10.1594/PANGAEA.883104 (Costas et al., 2017).

\section{Conclusions}

A new database, IBAM-Sed, including the textural characterization of sediment samples along the southern Atlantic coast of the Iberian Peninsula, is presented. The database compiles the results from 24 projects within a framework of which a total of 4727 samples were collected between 1996 and 2015. The compiled database includes samples from diverse sedimentary environments from emerged coastal barriers (including dunes) to the outer continental shelf, integrating sediments as well from estuaries, and a coastal lagoon.

The utility of the compiled database is demonstrated through three examples that show how this type of information can be used to characterize baseline conditions for further comparison analysis to assess the impact of anthropogenic activities within a basin over the surface distribution of sediments or even the impact from climate-related variability. Alternatively, the database is shown to contribute to decision making by providing the needed information during the selection of potential areas for dredging for nourishment purposes. Finally, it is shown how the database owns relevant information to apply morphodynamic models of beach classification as sediment texture states as one of the most important parameters in the determination of morphodynamic beach types.

Supplement. The supplement related to this article is available online at: https://doi.org/10.5194/essd-10-1185-2018-supplement.

Competing interests. The authors declare that they have no conflict of interest.

Acknowledgements. The authors would like to thank all people involved in the collection of the samples integrating the present database. Special thanks are given to Cornelia Behrens for her constant support through the process of archiving the database in PANGAEA. We also acknowledge Puertos del Estado (Ministerio de Fomento, Spain) for providing the access to the SIMAR database. Susana Costas is funded by the FCT Investigator programme (ref. IF/01047/2014). This work is a contribution to the UID/MAR/00350/2013 CIMA project.

Edited by: Hannes Grobe

Reviewed by: two anonymous referees

\section{References}

Ackermann, F., Bergmann, H., and Schleichert, U.: Monitoring of heavy metals in coastal and estuarine sediments - a question of grain-size: $<<20 \mu \mathrm{m}$ versus $<60 \mu \mathrm{m}$, Environ. Tech. Lett., 4, 317-328, https://doi.org/10.1080/09593338309384212, 1983.

Ahrens, J. P.: A Fall-Velocity Equation, J. Waterw. Port C., 126, 99-102, https://doi.org/10.1061/(ASCE)0733950X(2000)126:2(99), 2000.

Andrieux-Loyer, F. and Aminot, A.: Phosphorus Forms Related to Sediment Grain Size and Geochemical Characteristics in French Coastal Areas, Estuar. Coast. Shelf S., 52, 617-629, https://doi.org/10.1006/ecss.2001.0766, 2001.

Bagnold, R. A.: The Physics of Blown Sand and Desert Dunes, Methuen, London, 1941.

Bagnold, R. A.: The Flow of Cohesionless Grains in Fluids, Philos. T. R. Soc. A, 249, 235-297, https://doi.org/10.1098/rsta.1956.0020, 1956.

Bascom, W. N.: The relationship between sand size and beach-face slope, Eos T. Am. Geophys. Un., 32, 866-874, 1951.

Blott, S. J. and Pye, K.: GRADISTAT: a grain size distribution and statistics package for the analysis of unconsolidated sediments, Earth Surf. Proc. Land., 26, 1237-1248, https://doi.org/10.1002/esp.261, 2001.

Cahoon, L. B., Nearhoof, J. E., and Tilton, C. L.: Sediment grain size effect on benthic microalgal biomass in shallow aquatic ecosystems, Estuaries, 22, 735-741, https://doi.org/10.2307/1353106, 1999.

Chappell, J. and Eliot, I. G.: Surf-beach dynamics in time and space - An Australian case study, and elements of a predictive 
model, Mar. Geol., 32, 231-250, https://doi.org/10.1016/00253227(79)90066-5, 1979.

Costas, S., Ramires, M., Mendes de Paiva Pinto, I. M., Ferreira, Ó.: Surficial sediment texture from the Iberian Atlantic Margin Sediments Database (IBAM-Sed), PANGAEA, https://doi.org/10.1594/PANGAEA.883104, 2017.

Dias, J. M. A., Gonzales, R., and Ferreira, Ó.: Natural versus anthropic causes in variations of sand export from river basins: an example from the Guadiana River Mouth (Southwestern Iberia), Polish Geological Institute Special Papers, 11, 95-102, 2004.

Dolbeth, M., Ferreira, O., Teixeira, H., Marques, J. C., Dias, J. A., and Pardal, M. A.: Beach morphodynamic impact on a macrobenthic community along a subtidal depth gradient, Mar. Ecol. Prog. Ser., 352, 113-124, https://doi.org/10.3354/meps07040, 2007.

Domingues, R. B., Sobrino, C., and Galvão, H.: Impact of reservoir filling on phytoplankton succession and cyanobacteria blooms in a temperate estuary, Estuar. Coast. Shelf S., 74, 31-43, https://doi.org/10.1016/j.ecss.2007.03.021, 2007.

Domingues, R. B., Barbosa, A. B., and Galvão, H. M.: River damming leads to decreased phytoplankton biomass and disappearance of cyanobacteria blooms, Estuar. Coast. Shelf S., 136, 129-138, https://doi.org/10.1016/j.ecss.2013.11.012, 2014.

Finkl, C. W. and Walker, H. J.: Beach nourishment, in: Engineered Coasts, edited by: Chen, J., Eisma, D., and Walker, J., Kluwer, Dordrecht, the Netherlands, 2002.

Finkl, C. W. and Walker, H. J.: Beach Nourishment, in: Encyclopedia of Coastal Sciences, edited by: Schwartz, M. L., Springer Netherlands, 147-161, 2005.

Folk, R. L. and Ward, W. C.: Brazos River bar [Texas]; a study in the significance of grain size parameters, J. Sediment. Res., 27, 3-26, 1957.

Friedman, G. M. and Sanders, J. E.: Principles of Sedimentology, John Wiley and Sons, New York, 1978.

Gao, S. and Collins, M.: Net sediment transport patterns inferred from grain-size trends, based upon definition of "transport vectors", Sediment. Geol., 81, 47-60, https://doi.org/10.1016/00370738(92)90055-V, 1992.

Gao, S. and Collins, M. B.: Analysis of Grain Size Trends, for Defining Sediment Transport Pathways in Marine Environments, J. Coast. Res., 10, 70-78, 1994.

Garel, E., Sousa, C., Ferreira, Ó., and Morales, J. A.: Decadal morphological response of an ebb-tidal delta and down-drift beach to artificial breaching and inlet stabilisation, Geomorphology, 216, 13-25, https://doi.org/10.1016/j.geomorph.2014.03.031, 2014.

Garel, E.: Present dynamics of the Guadiana estuary, in: GUADIANA RIVER ESTUARY, Investigating the past, present and future, edited by: Moura, D., Gomes, A., Mendes, I., and Aníbal, J., University of Algarve, Faro, Portugal, 15-38, 2017.

Gibson, R. N. and Robb, L.: The relationship between body size, sediment grain size and the burying ability of juvenile plaice, Pleuronectes platessa L, J. Fish Biol., 40, 771-778, https://doi.org/10.1111/j.1095-8649.1992.tb02623.x, 1992.

Gonzalez, R., Dias, J. M. A., Lobo, F., and Mendes, I.: Sedimentological and paleoenvironmental characterisation of transgressive sediments on the Guadiana Shelf (Northern Gulf of Cadiz, SW Iberia), Quatern. Int., 120, 133-144, https://doi.org/10.1016/j.quaint.2004.01.012, 2004.
Gyllencreutz, R., Mahiques, M. M., Alves, D. V. P., and Wainer, I. K. C.: Mid- to late-Holocene paleoceanographic changes on the southeastern Brazilian shelf based on grain size records, The Holocene, 20, 863-875, https://doi.org/10.1177/0959683610365936, 2010.

Krumgalz, B. S.: Unusual grain size effect on trace metals and organic matter in contaminated sediments, Mar. Pollut. Bull., 20, 608-611, https://doi.org/10.1016/0025-326X(89)90397-4, 1989.

Le Roux, J. P.: Net sediment transport patterns inferred from grain-size trends, based upon definition of "transport vectors" - comment, Sediment. Geol., 90, 153-156, https://doi.org/10.1016/0037-0738(94)90022-1, 1994.

Le Roux, J. P. and Rojas, E. M.: Sediment transport patterns determined from grain size parameters: Overview and state of the art, Sediment. Geol., 202, 473-488, https://doi.org/10.1016/j.sedgeo.2007.03.014, 2007.

Lindhorst, S. and Betzler, C.: The climate-archive dune: Sedimentary record of annual wind intensity, Geology, 44, 711-714, https://doi.org/10.1130/g38093.1, 2016.

Look, B.: Handbook of geotechnical investigation and design tables, Taylor \& Francis London, 2007.

Masselink, G. and Short, A. D.: The Effect of Tide Range on Beach Morphodynamics and Morphology: A Conceptual Beach Model, J. Coast. Res., 9, 785-800, 1993.

McLachlan, A.: Physical factors in benthic ecology: effects of changing sand particle size on beach fauna, Mar. Ecol. Prog. Ser., 131, 205-217, 1996.

Morais, P.: Review on the major ecosystem impacts caused by damming and watershed development in an Iberian basin (SWEurope): focus on the Guadiana estuary, Ann. Limnol.-Int. J. Lim., 44, 105-117, 2008.

Rijn, L. C.: Principles of sediment transport in rivers, estuaries, and coastal seas, Aqua Publications, Amsterdam, the Netherlands, 1993.

Rocha, C., Galvão, H., and Barbosa, A.: Role of transient silicon limitation in the development of cyanobacteria blooms in the Guadiana estuary, south-western Iberia, Mar. Ecol. Prog. Ser., 228, 35-45, 2002.

Rosa, F., Rufino, M. M., Ferreira, Ó., Matias, A., Brito, A. C., and Gaspar, M. B.: The influence of coastal processes on inner shelf sediment distribution: The Eastern Algarve Shelf (Southern Portugal), Geol. Acta, 11, 59-73, 2013.

Shields, A.: Anwendung der Aehnlichkeitsmechanik und der Turbulenzforschung auf die Geschiebebewegung, TU Delft, Berlin, Deutschland, PhD Thesis, Technical University Berlin, 26 pp., 1936.

Short, A. D.: Wave Power and Beach-Stages: A Global Model, 16th International Conference on Coastal Engineering, Hamburg, 1145-1162, 1978.

Short, A. D.: Beaches, in: Handbook of Beach and Shoreface Morphodynamics, edited by: Short, A. D., John Wiley \& Sons Ltd, 3-20, 1999.

Soulsby, R.: Dynamics of marine sands, Dynamics of marine sands, Thomas Telford Ltd, 1997.

Sunamura, T.: Quantitative predictions of beach-face slopes, Geol. Soc. Am. Bull., 95, 242-245, 1984.

Terzaghi, K., Peck, R. B., and Mesri, G.: Soil mechanics in engineering practice, John Wiley \& Sons, 1996. 
Vandenberghe, J.: Grain size of fine-grained windblown sediment: A powerful proxy for process identification, Earth-Sci. Rev., 121, 18-30, https://doi.org/10.1016/j.earscirev.2013.03.001, 2013.

Wright, L. D. and Short, A. D.: Morphodynamic variability of surf zones and beaches: a synthesis, Mar. Geol., 56, 93-118, 1984.

Wright, L. D. and Thom, B. G.: Coastal depositional landforms:a morphodynamic approach, Prog. Phys. Geog., 1, 412-459, https://doi.org/10.1177/030913337700100302, 1977.
Wright, L. D., Chappell, J., Thom, B. G., Bradshaw, M. P., and Cowell, P.: Morphodynamics of reflective and dissipative beach and inshore systems: Southeastern Australia, Mar. Geol., 32, 105140, https://doi.org/10.1016/0025-3227(79)90149-X, 1979.

Yang, S. L., Li, H., Ysebaert, T., Bouma, T. J., Zhang, W. X., Wang, Y. Y., Li, P., Li, M., and Ding, P. X.: Spatial and temporal variations in sediment grain size in tidal wetlands, Yangtze Delta: On the role of physical and biotic controls, Estuar. Coast. Shelf S. 77, 657-671, https://doi.org/10.1016/j.ecss.2007.10.024, 2008. 